\title{
Editorial
}

\section{Workforce needs for endovascular acute ischemic stroke therapy: myth or reality?}

\author{
Harry Cloft, M.D., Ph.D. \\ Departments of Radiology and Neurosurgery, Mayo Clinic, Rochester, Minnesota
}

\begin{abstract}
The acute ischemic strokes amenable to intraarterial therapy probably number no more than 20,000 per year in the United States. The future demand for intraarterial reperfusion techniques may change, but the fraction of patients who require intraarterial thrombolysis is currently rather low, and the number of neurointerventionists is adequate. Each hospital caring for patients with acute stroke will need to determine its own demand for intraarterial therapy and employ an adequate supply of qualified neurointerventionists available to meet demand. Comprehensive stroke centers are now being designated and hopefully will foster a rational, regionalized approach to the delivery of endovascular therapies for stroke.

(http://thejns.org/doi/abs/10.3171/2013.9.FOCUS13372)
\end{abstract}

KEY WORDS - ischemic stroke - endovascular therapy • neurointervention

A CUTE ischemic stroke is a complex entity with many forms and many corresponding treatments that must be tailored to the individual patient. Consensus guidelines from the American Heart Association and American Stroke Association regarding acute ischemic stroke mention intraarterial therapy as one of many tools in the armamentarium for ischemic stroke. ${ }^{1}$ The rapid evolution of intraarterial therapy for ischemic stroke has led to speculation regarding the availability of a sufficient number of operators to treat patients in the United States (US). ${ }^{14,15,37,38}$ Stroke is the fourth leading cause of death in the US, after heart disease, cancer, and lung disease, ${ }^{32}$ so it is tempting to speculate that the number of neurointerventions for stroke must be headed for rapid expansion.

\section{The Demand for Intraarterial Stroke Therapy}

A rejection of the need for expansion of neurointerventional services for stroke might be regarded as a callous disregard for the needs of more than 795,000 Americans $^{32}$ who face death and disability from stroke each and every year. Based on the available relevant statistics, however, it is not. Intraarterial therapy is currently applicable to a small subset of patients with ischemic stroke. Hirsch et al. ${ }^{22}$ recently estimated 10,400-41,500 potential endovascular acute ischemic stroke intervention cases per year. In the Mayo Clinic analysis of demand for endovascular intervention for acute ischemic stroke in the US, we found that the demand is quite likely to be less than 20,000 cases per year, ${ }^{11}$ which fits nicely within the range estimated by Hirsch and colleagues. ${ }^{22}$ An additional factor not considered in previous estimates is that advanced stroke imaging has significant potential to reduce the number of endovascular treatments, because it could exclude many patients with completed infarctions from futile recanalization therapy.

A recent series of negative trial results for endovascular therapies is certainly not going to stimulate their use in acute ischemic stroke. The MR RESCUE (Mechanical Retrieval and Recanalization of Stroke Clots Using Embolectomy), ${ }^{26}$ SYNTHESIS (Local Versus Systemic Thrombolysis for Acute Ischemic Stroke), ${ }^{9}$ and IMS III (Interventional Management of Stroke III) ${ }^{8}$ trials all found a lack of benefit from endovascular therapy for acute ischemic stroke. It is clear from these trials that the application of endovascular therapy to a broad clinical cohort of acute ischemic stroke patients is not efficacious. These trial results should cause all endovascular stroke therapists to realize that careful patient selection is essential to good outcomes. Improving selection boils down to avoiding the treatment of those for whom endovascular recanalization is futile. ${ }^{710,23,31}$ Patient selection may be improved by advanced imaging, such as $\mathrm{MRI}^{27}$ or CT perfusion imaging, ${ }^{17}$ but this hypothesis remains to be conclusively evaluated. . $^{1,25,33,36,39,40}$ New technology such as stent-trievers cannot be expected 
to inevitably stimulate very much growth of endovascular treatment. Rather, these new endovascular technologies are replacing old ones, with probably little net growth in case numbers.

\section{The Supply of Intraarterial Stroke Therapy Providers}

An optimal number of practitioners in any medical specialty maximizes patient access to care while providing enough patients for each specialist to maintain his or her clinical expertise. Analysis of the neurointerventional workforce has been conducted for more than a decade, with initial work on this subject estimating that the optimal number of neurointerventionalists might be 600 in the US. ${ }^{12}$

While several papers in the cardiology literature have claimed that a shortage of neurointerventionalists would require cardiologists to provide endovascular therapy for acute ischemic stroke, ${ }^{14,15,37}$ there is actually no evidence that such a shortage exists. The number of neurointerventionalists was noted to be approaching 800 in 2012,,$^{16,41}$ and with 80-100 fellows finishing training each year recently, ${ }^{16}$ the number continues to grow. The 800 practitioners now make neurointerventional services available within 50 miles of $95 \%$ of the population. ${ }^{41}$

The optimal way to serve patients in sparsely populated areas and at smaller community hospitals is not to expect that we can staff them with a neurointerventionalist who is inactive all year except for the 1 or 2 instances in which someone needs neurointerventional treatment, when he or she would spring into action as a rather unpracticed operator. It is also not in the best interest of patients to expect that a non-neurointerventionalist is going to be able to expertly offer neurointerventional services after attending a hands-on workshop or other minimal training. The most practical solution is to rapidly transfer patients to regional centers that have volumes of patients to justify employing a neurointerventionalist who handles enough cases to maintain a high skill level. Aside from the neurointerventionalist's skill, high-volume stroke centers have better clinical outcomes and lower mortality than low-volume centers. ${ }^{34,35}$

\section{Planning for the Future}

The delivery of stroke care is analogous to that of trauma care in that a regional system is needed to provide prompt, skilled management to as much of the population as is practical. A regional care model has also been applied to myocardial infarctions but has not been implemented on a national level as in trauma. ${ }^{24}$ Regional trauma centers have been designated throughout the US and have been shown to improve outcomes. ${ }^{13}$ The number of Level I trauma centers in the US is $190 .{ }^{29}$ Comprehensive stroke centers are now being designated to serve a function analogous to trauma centers. If each of an estimated 200 comprehensive stroke centers treated 100 patients per year with intraarterial thrombolysis, 20,000 individuals would be treated annually in the US. That translates to $2.5 \%$ of the 795,000 patients hospitalized for acute is- chemic stroke in the US each year who could be treated with intraarterial methods. If each comprehensive stroke center were staffed by 3 neurointerventionists, the total number of required neurointerventionists would be approximately 600.

Because stroke is a major health problem, it is essential that skilled care be available from qualified neurological experts. Qualification standards have already been published as agreed on by a multidisciplinary coalition consisting of the Society of NeuroInterventional Surgery (SNIS), American Academy of Neurology, American Association of Neurological Surgeons/Congress of Neurological Surgeons Cerebrovascular Section, and Society of Vascular and Interventional Neurology. ${ }^{30}$ It is rather naive to assume that advanced stroke care can be delivered by physicians without expertise in the neurosciences. Each acute stroke center that offers intraarterial ischemic stroke therapy must ensure that qualified individuals are providing this therapy.

For patients with complex medical problems, studies have repeatedly and consistently shown that morbidity and mortality rates tend to be lower when treatment is provided at centers that care for large numbers of patients. ${ }^{3-5,20,21,28}$ This trend toward better outcomes with treatment at high-volume centers also holds true for patients who undergo endovascular therapy for acute ischemic stroke. Patients have been shown to be more likely to have successful reperfusion and a good clinical outcome if treated at a high-volume center. ${ }^{19}$

It might be argued that recanalization in acute ischemic stroke is such an urgent imperative that it is necessary to enlist the help of operators who are not specialized neurointerventionalists. There is often a misconception that endovascular treatment cannot possibly make things any worse than they already are. But misguided and unskilled intervention can certainly make the patient worse in many cases, and I remain skeptical that endovascular ischemic stroke intervention practiced outside of a specialized stroke center will help more patients than it harms. I find ischemic stroke cases to be among the most challenging neurointerventions, not just from a technical perspective but also from a cognitive decision-making perspective. While there may be anecdotal reports of patients recovering well after treatment by nonspecialized interventionalists, overall outcomes will probably be optimized by sending as many patients as possible for treatment at specialized stroke centers. Until recently, the SNIS mission statement was as follows: "The mission of [SNIS] is to foster the growth of the discipline of neurointervention and support its multi-disciplinary physician members to provide the highest quality of neurointerventional patient care through research, education, standard-setting, and advocacy" (http://www.snisonline.org/mission [accessed August 16, 2013]). At some point, fostering the growth of the discipline starts to conflict with providing the highest quality of neurointerventional patient care. Providing the highest-quality care should be the fundamental mission, and fostering the growth of the discipline should only be implemented if and when it promotes the highest quality of patient care. The number of operators has grown beyond an optimal level, resulting in a decline in quality. ${ }^{16}$ 
For example, in 2010, cerebral aneurysm treatments began to shift toward low-volume centers, probably because of an excessive number of treating physicians entering practice. ${ }^{6}$ Safety is fostered by having skillful operators at experienced centers, so maintaining an appropriate number of qualified practitioners is imperative.

The neurointerventional field finds itself in a position similar to American medicine a century ago. In the 19th century, medical education was largely unregulated and there were too many medical schools in the US. Following the release of an influential report by Abraham Flexner in 1910, educational standards were established and the number of medical schools was substantially reduced. ${ }^{2}$ These changes marked a turning point in the reputation of physicians among the general public. Like physicians in the early 20th century, neurointerventionalists are rather undefined and unregulated. There is no consensus standard of what qualifies a person to perform neurointerventional procedures. Board certification is the means by which fully mature specialties define qualified practitioners, and the neurointerventional field has not been able to reach this level of maturity for political reasons. While certification of fellowships was implemented by the Accreditation Council for Graduate Medical Education in 2006, such accreditation has not been sought by the majority of fellowships.

\section{Conclusions}

The number of acute ischemic strokes amenable to intraarterial therapy is probably no more than 20,000 per year in the US. The future demand for intraarterial reperfusion techniques may change, but the fraction of patients who require intraarterial thrombolysis is currently rather low, and the number of neurointerventionists is adequate. Each hospital caring for patients with acute stroke will need to determine its own demand for intraarterial therapy and employ an adequate supply of qualified neurointerventionists available to meet this demand. Comprehensive stroke centers are now being designated and hopefully will foster a rational, regionalized approach to the delivery of endovascular therapies for stroke.

\section{References}

1. Adams HP Jr, del Zoppo G, Alberts MJ, Bhatt DL, Brass L, Furlan A, et al: Guidelines for the early management of adults with ischemic stroke: a guideline from the American Heart Association/American Stroke Association Stroke Council, Clinical Cardiology Council, Cardiovascular Radiology and Intervention Council, and the Atherosclerotic Peripheral Vascular Disease and Quality of Care Outcomes in Research Interdisciplinary Working Groups. Circulation 115:e478-e534, 2007

2. Barzansky B: Abraham Flexner and the era of medical education reform. Acad Med 85 (9 Suppl):S19-S25, 2010

3. Birkmeyer JD, Siewers AE, Finlayson EV, Stukel TA, Lucas FL, Batista I, et al: Hospital volume and surgical mortality in the United States. N Engl J Med 346:1128-1137, 2002

4. Birkmeyer JD, Stukel TA, Siewers AE, Goodney PP, Wennberg DE, Lucas FL: Surgeon volume and operative mortality in the United States. N Engl J Med 349:2117-2127, 2003

5. Boudourakis LD, Wang TS, Roman SA, Desai R, Sosa JA: Evolution of the surgeon-volume, patient-outcome relationship. Ann Surg 250:159-165, 2009

6. Brinjikji W, Lanzino G, Kallmes DF, Cloft HJ: Cerebral aneu- rysm treatment is beginning to shift to low volume centers. $\mathbf{J}$ Neurointerv Surg [epub ahead of print], 2013

7. Brinjikji W, Rabinstein AA, Kallmes DF, Cloft HJ: Patient outcomes with endovascular embolectomy therapy for acute ischemic stroke: a study of the national inpatient sample: 2006 to 2008. Stroke 42:1648-1652, 2011

8. Broderick JP, Palesch YY, Demchuk AM, Yeatts SD, Khatri P, Hill MD, et al: Endovascular therapy after intravenous t-PA versus t-PA alone for stroke. N Engl J Med 368:893-903, 2013

9. Ciccone A, Valvassori L, Nichelatti M, Sgoifo A, Ponzio M, Sterzi R, et al: Endovascular treatment for acute ischemic stroke. N Engl J Med 368:904-913, 2013

10. Cloft HJ: Death and destruction in the intra-arterial battle with acute ischemic stroke. AJNR Am J Neuroradiol 32: 1769-1770, 2011

11. Cloft HJ, Rabinstein A, Lanzino G, Kallmes DF: Intra-arterial stroke therapy: an assessment of demand and available work force. AJNR Am J Neuroradiol 30:453-458, 2009

12. Cloft HJ, Tomsick TA, Kallmes DF, Goldstein JH, Connors JJ: Assessment of the interventional neuroradiology workforce in the United States: a review of the existing data. AJNR Am J Neuroradiol 23:1700-1705, 2002

13. Demetriades D, Martin M, Salim A, Rhee P, Brown C, Chan L: The effect of trauma center designation and trauma volume on outcome in specific severe injuries. Ann Surg 242:512519,2005

14. DeVries JT, White CJ, Collins TJ, Jenkins JS, Reilly JP, Grise MA, et al: Acute stroke intervention by interventional cardiologists. Catheter Cardiovasc Interv 73:692-698, 2009

15. DeVries JT, White CJ, Cunningham MC, Ramee SR: Catheter-based therapy for acute ischemic stroke: a national unmet need. Catheter Cardiovasc Interv 72:705-709, 2008

16. Fiorella D, Hirsch JA, Woo HH, Rasmussen PA, Shazam Hussain M, Hui FK, et al: Should neurointerventional fellowship training be suspended indefinitely? J Neurointerv Surg 4: 315-318, 2012

17. Fox AJ, Symons SP, Howard P, Yeung R, Aviv RI: Acute stroke imaging: CT with CT angiography and CT perfusion before management decisions. AJNR Am J Neuroradiol 33:792794,2012

18. Goyal M, Almekhlafi MA: Dramatically reducing imaging-torecanalization time in acute ischemic stroke: making choices. AJNR Am J Neuroradiol 33:1201-1203, 2012

19. Gupta R, Horev A, Nguyen T, Gandhi D, Wisco D, Glenn BA, et al: Higher volume endovascular stroke centers have faster times to treatment, higher reperfusion rates and higher rates of good clinical outcomes. J Neurointerv Surg 5:294-297, 2013

20. Halm EA, Lee C, Chassin MR: Is volume related to outcome in health care? A systematic review and methodologic critique of the literature. Ann Intern Med 137:511-520, 2002

21. Hewitt M: Interpreting the Volume-Outcome Relationship in the Context of Health Care Quality: Workshop Summary. Washington, DC: Institute of Medicine, 2000

22. Hirsch JA, Yoo AJ, Nogueira RG, Verduzco LA, Schwamm LH, Pryor JC, et al: Case volumes of intra-arterial and intravenous treatment of ischemic stroke in the USA. J Neurointerv Surg 1:27-31, 2009

23. Hussein HM, Georgiadis AL, Vazquez G, Miley JT, Memon MZ, Mohammad YM, et al: Occurrence and predictors of futile recanalization following endovascular treatment among patients with acute ischemic stroke: a multicenter study. AJNR Am J Neuroradiol 31:454-458, 2010

24. Jollis JG, Roettig ML, Aluko AO, Anstrom KJ, Applegate RJ, Babb JD, et al: Implementation of a statewide system for coronary reperfusion for ST-segment elevation myocardial infarction. JAMA 298:2371-2380, 2007

25. Kidwell CS: MRI biomarkers in acute ischemic stroke: a conceptual framework and historical analysis. Stroke 44:570578,2013 
26. Kidwell CS, Jahan R, Gornbein J, Alger JR, Nenov V, Ajani Z, et al: A trial of imaging selection and endovascular treatment for ischemic stroke. N Engl J Med 368:914-923, 2013

27. Lansberg MG, Straka M, Kemp S, Mlynash M, Wechsler LR, Jovin TG, et al: MRI profile and response to endovascular reperfusion after stroke (DEFUSE 2): a prospective cohort study. Lancet Neurol 11:860-867, 2012

28. Luft HS, Garnick DW, Mark DH, McPhee SJ: Hospital Volume, Physician Volume, and Patient Outcomes: Assessing the Evidence. Ann Arbor, MI: Health Administration Press Perspectives, 1990

29. MacKenzie EJ, Hoyt DB, Sacra JC, Jurkovich GJ, Carlini AR, Teitelbaum SD, et al: National inventory of hospital trauma centers. JAMA 289:1515-1522, 2003

30. Meyers PM, Schumacher HC, Alexander MJ, Derdeyn CP, Furlan AJ, Higashida RT, et al: Performance and training standards for endovascular ischemic stroke treatment. AJNR Am J Neuroradiol 31:E8-E11, 2010

31. Molina CA: Futile recanalization in mechanical embolectomy trials: a call to improve selection of patients for revascularization. Stroke 41:842-843, 2010

32. Roger VL, Go AS, Lloyd-Jones DM, Benjamin EJ, Berry JD, Borden WB, et al: Heart disease and stroke statistics-2012 update: a report from the American Heart Association. Circulation 125: $2-\mathrm{e} 220,2012$

33. Sanelli PC, Sykes JB, Ford AL, Lee JM, Vo KD, Hallam DK: Imaging and treatment of patients with acute stroke: an evidence-based review. AJNR Am J Neuroradiol [epub ahead of print], 2013

34. Saposnik G, Baibergenova A, O'Donnell M, Hill MD, Kapral MK, Hachinski V: Hospital volume and stroke outcome: does it matter? Neurology 69:1142-1151, 2007

35. Saposnik G, Jeerakathil T, Selchen D, Baibergenova A, Hachinski V, Kapral MK: Socioeconomic status, hospital volume, and stroke fatality in Canada. Stroke 39:3360-3366, 2008
36. Sheth KN, Terry JB, Nogueira RG, Horev A, Nguyen TN, Fong AK, et al: Advanced modality imaging evaluation in acute ischemic stroke may lead to delayed endovascular reperfusion therapy without improvement in clinical outcomes. J Neurointerv Surg 5 Suppl 1:i62-i65, 2013

37. White CJ, Abou-Chebl A, Cates CU, Levy EI, McMullan PW, Rocha-Singh K, et al: Stroke intervention: catheter-based therapy for acute ischemic stroke. J Am Coll Cardiol 58:101116,2011

38. White CJ, Cates CU, Cowley MJ, Weiner BH, Carpenter JS, Hopkins LN, et al: Interventional stroke therapy: current state of the art and needs assessment. Catheter Cardiovasc Interv 70:471-476, 2007

39. Wintermark M, Sanelli P, Meltzer CC: Stroke imaging: diffusion, perfusion, but no more confusion! AJNR Am J Neuroradiol [epub ahead of print], 2013

40. Wintermark M, Sanelli PC, Albers GW, Bello J, Derdeyn C, Hetts SW, et al: Imaging recommendations for acute stroke and transient ischemic attack patients: a joint statement by the American Society of Neuroradiology, the American College of Radiology, and the Society of NeuroInterventional Surgery. AJNR Am J Neuroradiol [epub ahead of print], 2013

41. Zaidat OO, Lazzaro M, McGinley E, Edgell RC, Nguyen T, Linfante I, et al: Demand-supply of neurointerventionalists for endovascular ischemic stroke therapy. Neurology 79 (13 Suppl 1):S35-S41, 2012

Manuscript submitted August 22, 2013

Accepted September 5, 2013.

Please include this information when citing this paper: DOI: 10.3171/2013.9.FOCUS13372.

Address correspondence to: Harry Cloft, M.D., Ph.D., Department of Radiology, Mayo Clinic, 200 1st St. SW, Rochester, MN 55905. email: cloft.harry@mayo.edu. 